\title{
The role of entertainment in engagement with climate change
}

Kieren Topp ${ }^{1}$, Michael Thai ${ }^{2}$ and Deanne H Hryciw ${ }^{1}$

\section{Corresponding Author:}

Deanne H. Hryciw, Griffith University, Nathan, Queensland, QLD, 4111, AUSTRALIA Email: d.skelly@griffith.edu.au 



\section{Abstract}

4 The blending of entertainment and education is often used as a mechanism for

5 communicating science to the general public. Key to dissemination of scientific

6 information is cognitive engagement of the audience with the content. The authors describe

7 a study investigating the relationship between entertaining videos and cognitive

8 engagement of the viewer on a topic associated with climate change. Two identical videos

9 discussing the science of climate change were created, with one video containing additional

10 content that was entertaining and based on popular cultural references. Viewers completed

11 an online survey $(\mathrm{n}=472)$ and the data demonstrated that there was no direct link between

12 presentation of the climate change information in an entertaining video and an individual's

13 level of cognitive engagement with the content. Further, that an indirect link was identified

14 so that perceived entertainment increased cognitive engagement. These findings may be

15 useful for communicators of environmental issues, especially with consideration of the

16 development of the field of edutainment.

18 Key words

19 climate change, videos, entertainment, engagement 


\section{Introduction}

23 The dissemination of scientific information can be used as a basis to inform the public and

24 influence their life choices (McKinnon et al., 2018). Currently, public awareness of

25 scientific information is limited due to the presentation of science in platforms such as

26 peer-reviewed journals and conferences, which often rely upon highly specialized

27 terminology and jargon (Schafer, 2011). Effective communication of science, in clear and

28 accurate terms, which summarize the key findings of research outcomes and is

29 understandable to the lay public, is therefore required to increase public awareness

30 (Scheufele, 2013). Methods for dissemination of science and scientific information to the

31 general public have incorporated a variety of strategies to engage interest in science

32 (Scheufele, 2013).

34 Climate change is an important issue, with the impacts of climate change a global challenge

35 (Schmid-Petri et al., 2017). Scepticism towards climate change is present in many societies

36 (Dunlap and McCright, 2008), which has led to people becoming wary of information

37 shared about the climate change. This scepticism has led to the development of questions

38 about how to best to communicate the issues associated with climate change to the public

39 (Moser, 2010). Various methods have been employed, with more recent focus in the area

40 of entertainment has been used to engage the general public in science.

42 Since the 1990s, there has been the development of entertainment platforms which allow

43 for the use of technology as a way of communicating educational information (Okan,

44 2003). Various platforms such as films, video, and computer games have been used to

45 present educational and scientific content (Dahlstrom, 2014). This has led to the 
46 development of a genera, edutainment, which relies upon visual material on a narrative

47 format and didactic styles, to engage the learner with the content (Buckingham and

48 Scanlon, 2000). The aim of edutainment is to engage the learner, via their emotions, in an

49 interactive pedagogy, which is centred around "fun" (Buckingham and Scanlon, 2000).

51 An emerging form of edutainment relies on video games to enhance education (e.g. Cai et

52 al., 2006), and develop cognitive engagement with the topic of interest (e.g. Dickey, 2005;

53 Filsecker and Hickey, 2014). However, Abraham and Jayemanne (2017) commented that

54 there are "very few (video) games telling stories that engage with climate change and the

55 unfolding ecological crisis" (pp 74). These authors further expressed that the majority of

56 video games do not have explicit narratives concerning climate change, but tend to embed

57 messages concerning climate change into the narrative focused on human-environment

58 relationships (Abraham and Jayemanne, 2017). Various other methods have been

59 employed to educate the public about climate change. Seminal work in the area of

60 education of the issues associated with climate change has relied on edutainment

61 presentations to the public on climate science (Flora et al., 2014). Specifically, these

62 studies aim to engage members of the public using presentations that incorporate

63 behavioral intentions and discussion with others/peers on the topic (Flora et al., 2014).

65 One limitation with these previous studies is that the relationship between entertainment

66 (to educate) and cognitive engagement of the viewer on climate change has not been

67 studied extensively. To answer this, we created two identical videos discussing the science

68 of climate change, with one video containing additional content that has imbedded 
69 edutainment in the form of cultural references. Following the random viewing of either

70 video, subjects' cognitive engagement in the content of the video was assessed, with

71 characteristics such as entertainment, age, education, political identity, or scientific literacy

72 used to predict cognitive engagement with the video content.

\section{$74 \quad$ Literature Review}

75 Communication of science on climate change

76 Communication of science has been gaining attention from policy makers, universities and

77 scholars (Royal Society, 2006). This has led to the evolution of models where members of

78 the general public have been encouraged to debate science policy (Bubela et al., 2009).

79 Learning about science can occur via formal or informal means, with informal activities

80 often termed "public awareness of science" (Burns et al., 2003). Increasing amounts of

81 scientific information are being made available for public scrutiny via popular media and

82 the internet.

84 Emerging data from the scientific community has demonstrated that humans are the 85 primary cause of current climate change (Intergovernmental Panel 86 on Climate Change (IPCC), 2014). Public discourse on the issue of climate change, where

87 a variety of factors, not the least of which is an ineffective ability to communicate

88 fundamental climate data to the general public, has contributed to widespread mistrust and

89 misunderstanding of scientists and their research (Somerville and Hassol, 2011). Many

90 have become wary of information shared about climate change, given the complexity of 
91 the phenomenon and the expansion of "fake news" concerning climate change (Cooper,

92 2011).

93

94 A challenge in this space is that science and scientific ideas can be complicated, and 95 communication of these ideas often becomes muddied by discipline-specific jargon and

96 terminology. Communication of science to a general population requires careful attention

97 to language (Brownwell et al., 2013). Ensuring scientific messages about climate change

98 are portrayed using clear, easily understood language, is important for the dissemination of

99 such knowledge to the general public (Besley et al., 2017; Moni et al., 2007). Emerging

100 research has investigated the potential of entertainment to engage the public on scientific

101 issues.

102

\section{Edutainment}

104 Scientists, educators and policymakers are challenged by effective strategies to engage

105 members of the general public on matters such as climate change. Public concern and

106 interest in climate change peaked in 2007, and has since been declining in interest

107 (Stoutenborough et al., 2014). Key to maintaining interest and motivation is cognitive

108 engagement where engaged individuals are more likely to invest in their learning and

109 embrace the challenge of acquiring new knowledge (Milne and Otieno, 2006). One mode

110 of delivering scientific content to the general public that may increase engagement is

111 through the use of entertainment. Entertainment is recognized as a crucial element of the

112 public sphere that captures the attention of viewers and allows for relationships to be

113 formed (Adam, Allan, and Carter 2013). Although limited, there is some evidence to show 
114 that use of entertainment as a tool for educating the public about climate change may

115 increase engagement with the issue. Bore and Reid (2014) have shown that satire in theatre

116 can "promote active and positive engagement with climate change debates." Similarly,

117 satirical television talk shows have a small but significant effect on audiences who hold

118 strong pre-existing views, but a stronger effect on those with weaker pre-existing views,

119 and can be an alternative route for reaching otherwise unengaged viewers (Brewer and

120 McKnight 2015). More recent work in this area has relied on edutainment presentations to

121 the public on climate science (Flora et al., 2014), where engagement is developed using

122 presentations that incorporate behavioral intentions and discussion with others/peers on the

123 topic (Flora et al., 2014). However, investigation of the cognitive engagement associated

124 with these presentations on climate change have not been performed.

126 A blending of entertainment and content, or edutainment (Colace, et. al., 2006), aims to

127 support the transfer of (scientific and complex) knowledge via a variety of media such as

128 multimedia software, internet sites, music, films, video, computer games, and TV programs

129 (Colace et al, 2006). With increasingly fragmented consumption of media, where

130 individuals can choose exactly what they want to watch and when (Prior 2005), and rapidly

131 growing viewership on platforms such as YouTube, Netflix, and Facebook (Molla 2017),

132 it is important that scientific knowledge is accurately disseminated through these modern

133 forms of media.

134

135 The present research study aimed to address this gap by investigating the use of 136 entertainment in educational online videos. In addition, as there is currently limited 
137 research on the effect of entertainment on cognitive engagement of scientific knowledge

138 through online video, the second aim was to determine if cognitive engagement on the

139 topic was achieved through the video. Given that YouTube is the leading online video-

140 based social media platform worldwide, and is the most popular mode through which

141 videos are shared on the internet (Anderson and Jiang 2018), this platform was chosen for

142 the present study. Participants were presented with educational videos about climate

143 change that either included small clips from film and television (entertaining) or did not

144 include these clips. For this study, cognitive engagement is defined as the audience's ability

145 to retain information presented in the online video.

\section{Research Questions}

149 The aims of this present research are to:

150 A1. Characterize the effect of an "edutaining" video about climate change on perceived 151 entertainment.

152 A2. Characterize the effect of an "edutaining" video about climate change on cognitive 153 engagement.

154 A3. Identify if age, education, political identity, or scientific literacy predict the 155 engagement of the subjects with the "edutaining" video about climate change.

\section{Methods}

158 The videos 
159 The process for creating the videos involved a broad review of the literature on climate

160 change that was distilled to the most salient and relevant points. A narrative was created

161 from these points and turned into a film script for presenting. The videos were edited to

162 ensure they were standardized, such that the correct structure was consistent across the two

163 videos. The two videos were thus almost identical, except for the manipulation. The first

164 video contained educational content focused on the issue of climate change

165 (https://www.youtube.com/watch?v=c5juYFrTxJQ\&feature=youtu.be). The second video

166 contained the same educational content, plus five additional entertaining clips from film

167 and television (including politicians and popular movies) relevant to the content

168 (https://www.youtube.com/watch?v=CjpbZLVVwIA\&feature=youtu.be).

170 The first entertaining media clip played after the presenter in the video said, "Now, for

171 those of you who choose not to accept the overwhelming evidence for climate change...".

172 The video clip depicted Matthew McConaughey finishing the sentence with a line from the

1731994 movie Dazed and Confused - “...it would be a lot cooler if you did”. The second

174 entertaining media clip was an audio track that played while the presenter in the video was

175 depicted doing some quick calculations. The track was a snippet from Man's Not Hot by

176 Big Shaq.. When the presenter finished the calculations, the lyric "quick maths" was played

177 along with the words appearing on the screen. The third entertaining media clip was a three

178 second video clip of Trump during his 2016 presidential campaign claiming "We need

179 some global warming! It's freezing!" The fourth entertaining media clip was a cut of the

180 presenter of the video making a facetious comment. When discussing sea-level rise, the

181 presenter joked that those living near the coast should say goodbye, and to those who had 
182 never been, “...it's about to get a whole lot easier for you!” The final entertaining media

183 clip was a very short cut of the presenter doing an odd arm action which resembled a 'dab',

184 a style of hip hop dance that has now become popular on the internet. The words 'NOT A

185 DAB' appeared during this action.

186 These memes (a viral form of internet humor) were chosen for either their relevance to the

187 content or because they were currently trending, or 'viral' on the internet, fostering the 188 greatest chance of being relatable to the viewers.

190 The survey

191 The online survey was constructed using the Qualtrics platform (Appendix 1). Firstly, a

192 seven-question indicator test was administered to participants, to measure their current

193 level of science literacy and numeracy as a covariate to control for when ascertaining the

194 impact of the videos on cognitive engagement. The participant's score was a tally of correct

195 answers; no weighting was given to more or less difficult questions. This measure was

196 adapted from the National Science Foundation's Science and Engineering Indicators, as

197 used by Kahan et al. (2012).

199 After this, participants were randomly assigned to one of two YouTube videos: the 200 entertaining or non-entertaining control video. Immediately after the video, participants

201 were asked to rate how entertaining they perceived the video to be. This measure was

202 embedded among three other measures, including feelings of sadness due to the video,

203 belief of factual integrity of the video, and belief regarding whether the video was talking

204 about a topic focused on the negative impact of humans on climate change. 
206 Cognitive engagement was measured next, with twelve multi-choice or short-response

207 questions directly related to content presented in the video. No questions asked for opinions

208 or views other than verifiable facts that were presented in the video. The participant's score

209 was a tally of correct answers, with no weighting on any answers. This was the only

210 measure not adapted from previous instruments in the literature given that the questions

211 within it pertained to the videos developed specifically for this study.

213 The survey also contained filler questions that measured participants' risk perception of

214 the impact of climate change, perceived likelihood of climate change affecting the

215 participant (or their family, their society, and the world), attitudes towards greenhouse gas

216 reduction policies, trust in the science showing that climate change is primarily

217 anthropogenic, and intentions to take personal or political action to reduce climate impacts.

218 The risk perception measure was adapted from Kahan et al. (2012). The same wording was

219 used, but instead of a 10-point scale, we used a four-point scale: 1 no risk, 2 very little risk,

2203 moderate risk, 4 extreme risk. All other measures were adapted from those used by

221 McCright et al. (2016). These measures were not relevant to the present research question;

222 they were included out of interest, and to mask the purpose of the study.

223 Finally, demographic data was collected to better understand the population of participants,

224 and/or to include as covariates in the main analyses. Demographic data collected were the 225 participants age, gender identity, ethnic identity, education, current employment status, 226 household income, religiosity, and political orientation. 


\section{Analytical techniques}

229 The data was analyzed using the Statistical Package for the Social Sciences (SPSS).

230 ReMediation analyses were used to assess the impact of the video manipulation on the

231 dependent measures. The video manipulation was coded as a dichotomous variable $(0=$

232 entertaining video, $1=$ non-entertaining video). These analyses were run with the

233 PROCESS macro using bootstrapping procedures recommended by Hayes (2009), in order

234 to estimate both direct and indirect effects of the videos. Age, education, income, political

235 orientation, and pre-measured science literature and numeracy were included as covariates

236 in all analyses, given they have been demonstrated to influence attitudes, perceptions and

237 beliefs about climate change (e.g. Hamilton, 2011).

\section{Results}

\section{Sample population}

240 The sample size of 472 respondents was 58\% female and 91\% Caucasian. 59\% obtained

241 an education of at least one Bachelor degree or higher. The sample demonstrated a spread

242 of distribution of age, with a mean and median of about 41 and 47 years old respectively.

243 The majority of subjects identified as left-wing (64\%), with $13 \%$ identified as right wing

244 and the remaining $23 \%$ reporting no preference.

246 The survey was advertised in an equal number of Facebook groups holding advertised

247 views that were considered left- or right-wing, or having no particular preference. This was

248 achieved by targeting mostly groups with explicit support for a political party or leader, 
249 some pages that represented politically-polarized issues, and a couple pages claiming to be

250 a discussion point inclusive of left, right, and centrist people. No rewards were offered for

251 completing the survey; it was completed of participants' own volition.

\section{The effect of entertainment on cognitive engagement}

254 A mediation analysis tested the effect of type of video on cognitive engagement via level

255 of entertainment (Figure 1). Age, income, education, political identity, and science literacy

256 were controlled for. Participants who viewed the entertaining video reported significantly

257 greater perceived entertainment than participants who viewed the non-entertaining video

$258(p=0.002$, coefficient $=-0.425)$. Greater perceived entertainment was, in turn, significantly

259 associated with greater cognitive engagement $(\mathrm{p}=0.038$, coefficient $=0.059)$. Although

260 no direct effect of video type emerged on cognitive engagement (coefficient $=-0.007,95 \%$

261 CI [-0.1664, 0.1512]), an indirect effect of video type on cognitive engagement emerged

262 through perceived entertainment (coefficient $=-0.025,95 \%$ CI $[-0.0705,-0.0004]$ ),

263 indicating full mediation. That is, the entertaining video was associated with greater

264 cognitive engagement, through greater perceived entertainment.

266 The associations between the control variables and both perceived entertainment and

267 cognitive engagement were also observed (Table 1). Income, level of education, and

268 science literacy had no association with perceived entertainment. Age was associated with

269 perceived entertainment, such that younger participants reported greater entertainment

270 overall (coefficient $=-0.153, \mathrm{p}=0.036$ ). Science literacy was associated with cognitive

271 engagement, such those with greater science literacy were likely to score higher on

272 cognitive engagement (coefficient $=-0.110, \mathrm{p}=0.002$ ). Political identity was associated 
273 with both perceived entertainment and cognitive engagement, such that those who

274 identified as more left-wing reported greater entertainment overall (coefficient $=-0.145, p$

$275=0.009)$ and lower cognitive engagement overall (coefficient $=-0.097, p=0.003)$.

\section{Discussion}

279 Ensuring that the general public has an adequate understanding of scientific knowledge is

280 essential for the advancement of science as a whole. Communicators must rely on using

281 the most effective methods to get information across. Prior research covers outdated

282 technology like chatrooms, television news, and newspapers (Feldman, Hart 2017;

283 Mubaraka, Rohdeb and Pakulski 2009; Prior 2005). Media consumption via online video

284 is rapidly increasing (Molla 2017), so this research investigated the effect of entertainment

285 in online videos, and whether it can influence an individuals' cognitive engagement on the 286 topic.

288 This study found that, while there was no direct link between the entertaining video and an

289 individual's level of cognitive engagement, an indirect link was confirmed through their

290 perceived entertainment as a mediator. The entertaining video increased perceived

291 entertainment, and perceived entertainment increased cognitive engagement,

292 independently of political identity, age, and education levels (Hamilton 2011; Rainie et al.,

293 2015). This research can be expanded upon in future to solidify the effect of entertainment

294 in other areas of science communication in order to better our understanding of

295 communication techniques and reach wider audiences. 
297 The absence of a direct link between the entertaining video and cognitive engagement

298 could be explained by the presence of another mediator that has a negative effect on

299 cognitive engagement. For example, the entertaining video could have been distracting

300 enough to negate the positive effect of entertainment. Further research is needed to

301 investigate the relationship of distraction, or other possible negative mediators. A thorough

302 understanding of positive and negative mediators would enable communicators to create

303 more engaging and effective communication videos. The link between entertainment and

304 cognitive engagement within the topic of climate change may have applications in other

305 areas of science communication; for example, vaccination awareness, astrophysics

306 education, or socioscientific issues. Further research is required to solidify the relevance of

307 this link outside of the context of climate change communications.

309 Education and scientific literacy had no association with entertainment. This finding is important

310 because an individual's level of education has only a weak to medium effect on their

311 acceptance of climate change and energy topics (Rainie et al., 2015). Since individuals of

312 most levels of education can be prone to science denial, it is encouraging that the use of

313 entertainment as a tool is effective in reaching individuals of any educational background.

314 The respondents' age was negatively associated with perceived entertainment, which

315 confirms our research aim of addressing younger adults with entertainment. Political

316 identity was also associated with perceived entertainment (with participants identifying as

317 right-wing reporting lower perceived entertainment) and highlights the presence of 
318 cognitive biases that inhibit the individual's ability to accept information from opposing

319 views.

321 Our study demonstrated that political identity was associated with cognitive engagement.

322 Participants who identified as more left-wing were more cognitively engaged. This either

323 suggests that right-wing participants did not engage with either video as much as left-wing

324 participants, probably due to politically motivated rejection of climate change, or that right-

325 wing participants were already less familiar with the facts on climate change than left-wing

326 participants. Therefore, it was important that we controlled for political orientation, given

327 these effects. This, again, highlights the importance of understanding and breaking down

328 cognitive biases when communicators are attempting to reach an audience with a likely

329 predisposition against the information.

330

\section{Conclusion}

333 In conclusion, this study demonstrates that an indirect link occurred between the

334 entertaining videos and cognitive engagement, so that perceived entertainment increased

335 cognitive engagement associated with climate change. A strength of this study is that it

336 describes the use of popular culture edutainment, to engage with audiences on the topic of

337 climate change. These findings may be useful for communicators of environmental issues,

338 especially with consideration of the development of the field of edutainment. 
341 The present findings should be interpreted in light of the limitations in methodology and

342 design of the study. First, no pre-measure was included to assess prior level of

343 understanding or exposure to climate change information. Thus, some participants may

344 have already known the answers to the post-measure of cognitive engagement. This would

345 have had a negligible impact on the main findings for the video manipulation, however,

346 given that we randomly assigned participants to video type ensuring prior knowledge did

347 not systematically covary with experimental condition. We also administered a pre-

348 measured science literacy and numeracy test to control for prior knowledge in analyses

349 (presumably those higher in science literacy and numeracy would also have more

350 knowledge on climate change).

351

352 Another limitation was that, although there were qualitative differences between the

353 entertaining and non-entertaining videos, the differences between the videos were small

354 and took the form of just five short additional entertaining media clips. This was deemed

355 necessary to ensure the videos were similar in length but may have resulted in a weaker

356 effect of the video manipulation. Future research should attempt to create videos that are

357 equivalent in educational content, but more dramatically different in entertaining content

358 for a stronger effect of the video manipulation. The sample was somewhat homogenous,

359 being comprised of mostly Caucasian, college educated, and left-wing women. This limits

360 the generalizability of the findings, and further research in this area should be conducted

361 with more representative samples. 


\section{Acknowledgements}

363 The authors acknowledge XXX for his input into the content of the videos, Mr XXXX, for

364 his filming and video editing and the social media groups who allowed us to share the 365 survey for a broader reach.

\section{References}

367 Abraham, B., and Jayemanne, D. 2017. "Where are all the climate change games? Locating 368 digital games' response to climate change." Transformations. 30, 74-94.

369 Adam, B., Allan, S., and Carter, C. 2013. Environmental Risks and the Media. Routledge.

370 Anderson, A. 2009. "Media, Politics and Climate Change: Towards a New Research 371 Agenda." Sociology Compass, 3, 166-182.

372 Anderson, M., and Jiang, J. 2018. “Teens, Social Media and Technology 2018.” Pew 373 Research Center (May).

374 Besley, J.C., Dudo, A., and Yuan, S. 2018. "Scientists views about communication 375 objectives." Public Understanding of Science. 27, 708-730.

376 Bore, I. L. K., and Reid, G. 2014. "Laughing in the Face of Climate Change? Satire as a 377 Device for Engaging Audiences in Public Debate." Science Communication $378 \quad 36(4): 454-78$.

379 Brewer, P. R. and McKnight, J. 2015. "Climate as Comedy: The Effects of Satirical 380 Television News on Climate Change Perceptions." Science Communication $37(5): 635-57$.

382 Brownwell, S.E., Price, J.V., and Steinman, L. 2013. "Science Communication to the 383 General Public: Why We Need to Teach Undergraduate and Graduate Students this 

Neuroscience Education. 12, E6-E10.

386 Bubela, T., Nisbet, M.C., Borchelt, R., Brunger, F., Critchley, C., Einsiedel, E., Geller, G., Gupta, A., Hampel, J., Hyde-Lay, R., Jandciu, E.W., Jones, S.A., Kolopack, market place. Paper presented to the International Forum of Researchers on Young

Buckingham, D., and Scanlon, M. 2000. That is edutainment: media, pedagogy and the P., Lane, S., Lougheed, T., Nerlich, B., Ogbogu, U., O'Riordan, K., Ouellette, C., Spear, M., Strauss, S., Thavaratnam, T., Willemse, L., and Caulfield, T. 2009. "Science communication reconsidered." Nature Biotechnology, 27, 514-518. People and the Media, Sydney.

Burns, T.W., O'Connor, D.J., and Stocklmayer, S.M. 2003. "Science communication: a contemporary definition." Public Understanding of Science. 12, 183-202.

Cai, Y., Lu, B., Zheng, J., and Li, L. 2006. "Immersive protein gaming for bio edutainment". Simulation and Gaming. 37 (4) 466-475.

Colace, F., De Santo, M., and Pietrosanto, A. 2006. Work in Progress: Bayesian Networks for Edutainment, 36th ASEE/IEEE Frontiers in Education Conference, DOI: 10.1109/FIE.2006.322573.

Cooper, C. B. 2011. "Media Literacy as a Key Strategy towards Improving Public Acceptance of Climate Change Science." BioScience 61 (3):231-7. doi: 10.1525/bio.2011.61.3.8 $13614-13620$. 
407 Dickey, M.D. 2005. "Engaging by design: How engagement strategies in popular computer and video games can inform instructional design."Educational Technology Research and Development. 53 (2), 67-83.

410 Dunlap, R.E., and McCright, A.M. 2008. "A widening gap: Republican and democratic views on climate change." Environment: Science and Policy for Sustainable

413 Feldman, L., Hart, P. 2017. "Is There Any Hope? How Climate Change News Imagery and Text Influence Audience Emotions and Support for Climate Mitigation Policies." Risk Analysis. 38 (3), 505-602.

Filsecker, M., and Hickey, D. T. 2014. "A multilevel analysis of the effects of external rewards on elementary students' motivation, engagement, \& learning." Computers and Education, 75, 136-148.

419 Flora, J.A., Saphir, M., Lappe, M., Roser-Renouf, C., Maibach, E.W. and Leiserowitz, 420 A.A. 2014. "Evaluation of a national high school entertainment education program: The Alliance for Climate Education". Climatic Change. 127 (3-4) 419-434.

424 Hayes, A. F. 2009. "Beyond Baron and Kenny: Statistical Mediation Analysis in the New 425

426 Intergovernmental Panel on Climate Change (IPCC) (ed.) (2014) Fifth assessment report. $427 \quad$ Available at: www.ipcc.ch (accessed 2 May 2018).

428 Kahan, D. M., Peters, E., Wittlin, M., Slovic, P., Larrimore Ouellette, L. L., Braman, D. 429 and Mandel, G. 2012. "The Polarizing Impact of Science Literacy and Numeracy on 
431 McKinnon, M., Howes, J., Leach, A., and Prokop, N. 2018. "Perils and positives of science $432 \quad$ journalism in Australia." Public Understanding of Science. 27, 562-577.

433 McCright, A. M., Charters, M., Dentzman, K., and Thomas Dietz. 2016. "Examining the 434 Effectiveness of Climate Change Frames in the Face of a Climate Change Denial 435 Counter-Frame.” Topics in Cognitive Science 8(1):76-97.

436 Milne, C., and Otieno, T. 2006. "Understanding engagement: Science demonstrations and emotopnal energy." Science Education, 91, 523-553.

438 Molla, R. 2017. "People Consumed More Media than Ever Last Year — but Growth Is 439 Slowing." Recode. Retrieved December 11, 2017 $440 \quad$ (https://www.recode.net/2017/5/30/15712660/media-consumption-zenith-mobile441 internet-tv).

442 Moni, R.W., Hryciw, D.H., Poronnik, P., and Moni, K. 2007. "Using explicit teaching to 443 improve how bioscience students write to the lay public." Advances in Physiology $444 \quad$ Education. $31,167-175$

445 Moser, S. C. 2010. "Communicating Climate Change: History, Challenges, Process and 446 Future Directions." WIREs Climate Change 1 (1):31-53. doi: 10.1002/wcc.011

447 Mubaraka, A.R., Rohdeb, A., Pakulski, P. 2009. "GLOBAL: Students benefit from online $448 \quad$ chatrooms." Journal of Higher Education Policy and Management. 31 (2), 161$449 \quad 174$.

450 Okan, Z. 2003. "Edutainment: is learning at risk?" British Journal of Educational Training. $34,255-264$.

452 Prior, M. 2005. "News vs. Entertainment : Choice and Widens Turnout Gaps in Increasing 
Media Political Knowledge.” American Journal of Political Science 49(3):577-92.

454 Rainie, L., Funk, C., Kennedy, B., Anderson, M., Duggan, M., Olmstead, K., Perrin, A., 455 Greenwood, S., Suh, M., Porteus, M., and Page, D. 2015. "Americans, Politics and 456 Science Issues". Pew Research Centre (July).

457 Royal Society. 2006. Factors Affecting Science Communication: A Survey of Scientists and 458 Engineers. London, UK: The Royal Society.

459 Schäfer, M. 2011. "Sources, characteristics and effects of mass media communication on 460 science: A review of the literature, current trends and areas for future research." $461 \quad$ Sociology Compass 5, 399-412.

462 Scheufele, D.A. "Communicating science in social settings". Proceeding of the National $463 \quad$ Academy of Science.

464 Schmid-Petri, H., Adam, S., Schmucki, I., and Haussler, T. 2017. "A changing climate of 465 skepticism: The factors shaping climate change coverage in the US press." Public $466 \quad$ Understanding of Science. 26, 498-513.

467 Somerville, R.C., and Hassol, S. J. 2011. "Communicating the science of climate change." $468 \quad$ Physics Today. 64, 48-53.

469 Stoutenborough, J.W. Liu, X., and Vedlitz, A. 2014. "Trends in Public Attitudes Toward 470 Climate Change: The Influence of the Economy and Climategate on Risk, 471 Information, and Public Policy." Risk, Hazards and Crisis in Public Policy. 5,2247237.

473

474 475 
476 
Table 1 - Mediation analysis with variables predicting perceived entertainment and cognitive engagement

\begin{tabular}{|l|l|l|l|l|l|l|}
\hline \multirow{2}{*}{ Variable } & \multicolumn{4}{|l|}{ Perceived entertainment } & \multicolumn{4}{l|}{ Cognitive engagement } \\
\cline { 2 - 7 } & Coeff & SE & $\mathbf{p}$ & Coeff & SE & $\mathbf{p}$ \\
\hline Age & $-0.153^{*}$ & 0.073 & 0.036 & -0.028 & 0.043 & 0.517 \\
\hline Income & 0.015 & 0.042 & 0.720 & -0.014 & 0.025 & 0.557 \\
\hline Education & 0.020 & 0.056 & 0.729 & -0.009 & 0.033 & 0.785 \\
\hline $\begin{array}{l}\text { Political } \\
\text { Identity }\end{array}$ & $-0.145^{*}$ & 0.055 & 0.009 & $-0.097^{*}$ & 0.033 & 0.003 \\
\hline $\begin{array}{l}\text { Science } \\
\text { Literacy }\end{array}$ & -0.012 & 0.060 & 0.834 & $0.110^{*}$ & 0.035 & 0.002 \\
\hline Video & $-0.425^{*}$ & 0.136 & 0.002 & -0.007 & 0.080 & 0.925 \\
\hline $\begin{array}{l}\text { Perceived } \\
\text { Entertainment }\end{array}$ & & & & $0.059^{*}$ & 0.028 & 0.038 \\
\hline
\end{tabular}

Note: Coeff $=$ coefficient, $\mathrm{SE}=$ standard error, $\mathrm{p}(\mathrm{p}$-value $)$. 
Figure 1. Mediation model depicting the effect of video on cognitive engagement, through entertainment

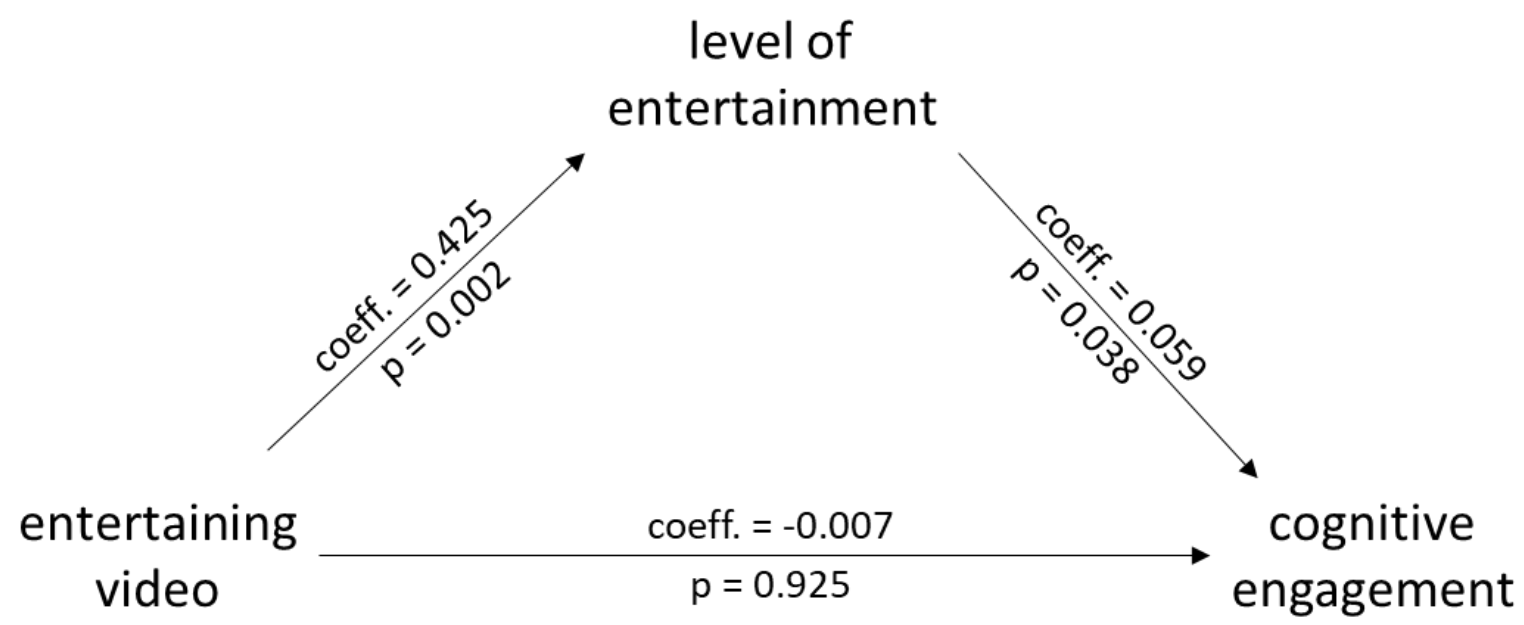

